for these exchanges, the panel warns, is limited by the recommended polyunsaturated to saturated ratio of 0.45 . Present British consumption of polyunsaturated fatty acids has reached $4.9 \%$ of food energy. The panel's recommendations work out to $7 \%$. For comparison the World Health Organisation report on coronary heart disease suggests up to $10 \%$ of dietary energy. ${ }^{18}$ The new report thus takes a moderate position on polyunsaturated fats, between the former Department and the joint reports. As the panel says, the polyunsaturated to saturated ratio that it recommends is common in many countries with a lower incidence of coronary heart disease and carries no obvious disadvantages, but the effects on the population of a ratio of 1 and beyond are unknown.

Advice on other dietary components follows in this order. The panel makes no specific recommendations about dietary cholesterol; it considers present intakes in Britain not excessive and likely to fall if saturated fat consumption is reduced. It recommends that intakes of "simple sugars" should not be increased-they are in fact falling-but does not mention any link with coronary heart disease. ${ }^{19}$ Excessive alcohol intake (over $80 \mathrm{~g} /$ day for men) is harmful in general and may adversely affect the cardiovascular system; the effects of low or moderate intakes have not been adequately tested. Salt intake is needlessly high in Britain: the panel says consideration should be given to ways of reducing it. It sees advantages in replacing the proposed reduction of dietary fat by eating more fibre rich bread, cereals, fruit, and vegetables. Obesity should be avoided or treated by appropriate food intake and regular exercise. The value of supplements of eicosapentaenoic acid requires more research and the panel cautions against their unsupervised use. Hardness of drinking water, emphasised in the 1974 DHSS report, gets no specific recommendations.

Britain has not shared in the declining mortality from coronary heart disease which started in the United States and is now being experienced in Australia, Belgium, Canada, Finland, New Zealand, Norway, and some other Western countries. Consequently Scotland, Northern Ireland, and England with Wales have moved up in the world league table of coronary deaths to second, third, and fifth positions respectively for men and first, second, and ninth positions for women. ${ }^{16}$ No reduction of average fat consumption has taken place in this country; from 1974 to 1982 it crept up from $40 \%$ to $41 \%$ of food energy, ${ }^{16}$ and plasma cholesterol concentrations may still be rising. ${ }^{20}$

The recommendations in the new report have been worked out carefully and objectively by a well balanced panel. They are consistent with the scientific evidence. Minor details of wording and the order of some recommendations may be criticised in the report, as can the unexplained discrepancy between fig 3.2 and table 3.1 and the statement that multiple risk factor intervention trials (mainly diet and smoking) have not shown convincing benefit. But here is a very sensible report. It should be the basis for concerted national action.

As the panel suggests, production of leaner meats should be encouraged and the government should consider how to remove from the Common Agricultural Policy those measures which conflict with prevention of coronary heart disease. All packaged foods should show their fat content and type on the label. More foods should be made available to the public with reduced saturated fat or salt or both. Research is needed into cheaper and simpler methods for measuring blood lipid values and blood pressure so that doctors may more readily assess their patients' coronary risk factors as suggested by Oliver. ${ }^{21}$ Health education in Britain has been ineffective so far in reducing coronary heart disease.

Doctors should be able to accept the conclusions of the 1984 report into the body of received medical knowledge"reduced saturated fat helps to prevent CHD" like "not smoking reduces lung diseases." If dissension and doubts in the British medical establishment about preventing coronary heart disease now diminish then journalists, dietitians, and schoolteachers can get on with their work of informing and educating people who have been confused. Food manufacturers and politicians will respond to public consensus and demand and Britain can at last expect a decline in premature deaths from coronary disease.

\section{A Stewart Truswell}

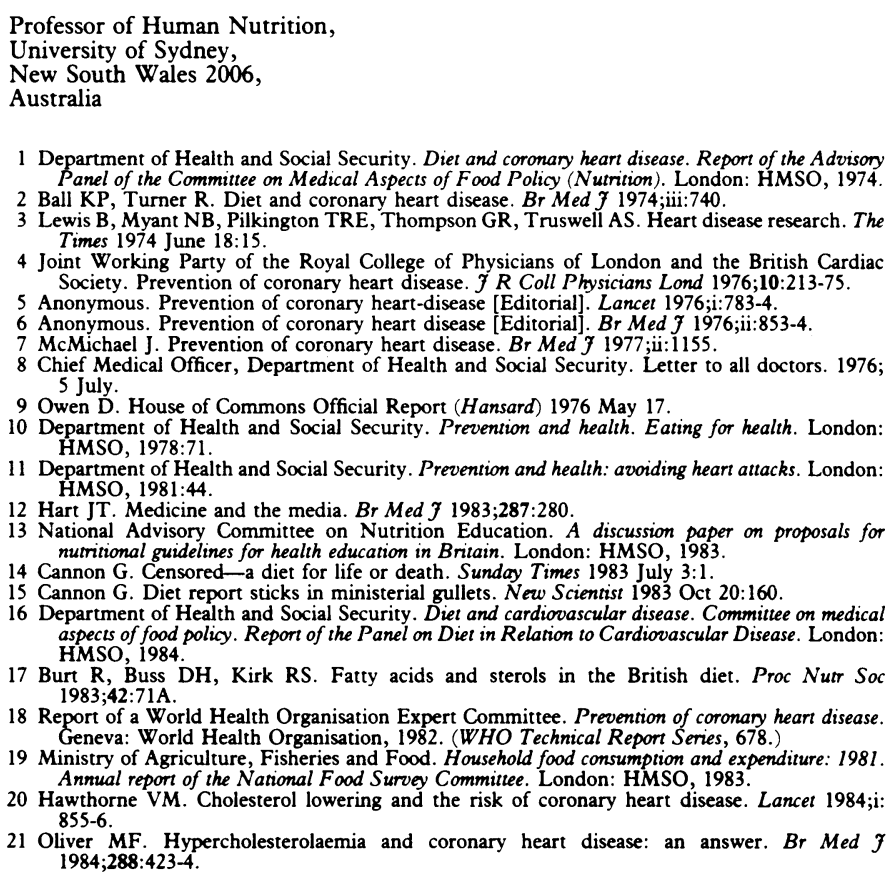

\section{Psittacosis}

"Sick as a parrot" has entered the vernacular, courtesy of the sporting press, and seems to be an oblique reference to psittacosis. The parrot may have been unduly maligned, as most cases of psittacosis may well be unconnected with parrots - or indeed other birds.

Chlamydia psittaci, the organism responsible for psittacosis, is an intracellular bacterium. It was originally thought to be a virus and is still listed as being synonymous with the "ornithosis virus" in the Index Medicus. Other obsolete names for the chlamydiae are bedsoniae and trachoma inclusion conjunctivitis agents. The chlamydiae have a unique two stage developmental cycle: fragile reticulate bodies are responsible for intracellular replication, and resilient elementary bodies permit transmission from one host cell to another.

The clinical presentation of psittacosis varies from a mild influenza-like illness to fulminating pneumonia complicated by lesions in other systems. Illness is most often described in adults aged $30-60$; it is only rarely reported in children. ${ }^{12}$ The incubation period is one to two weeks. The onset may be gradual with dry cough or abrupt with fever, shivering, sore throat, headache, and generalised myalgia. There may be a 
relative bradycardia. Classically the patient has a dry, unproductive cough, though rarely he may produce mucopurulent, rust coloured sputum. Crepitations are often heard but (as in mycoplasmal pneumonia) the radiological changes usually far exceed the physical signs. Patchy consolidation may persist on the chest $x$ ray film for several weeks after the resolution of symptoms. ${ }^{3}$ Extrapulmonary manifestations include vasculitic skin lesions resembling rose spots and epistaxis. Myocarditis ${ }^{4}$ and pericarditis 5 may occur; endocarditis ${ }^{67}$ is rare but may be fatal. ${ }^{7}$ Some patients are confused or semicomatose, and meningoencephalitis has been described.$^{8}$ Treatment is with tetracycline, for 21 days in severe cases; children should be given erythromycin. The endocarditis has been successfully treated with rifampicin. ${ }^{6}$

The diagnosis of psittacosis is almost exclusively serological. $C$ psittaci grows readily on cell monolayers, but it is a grade $B$ pathogen, and deaths have occurred in laboratory workers. ${ }^{9}$ The widely used complement fixation test does not distinguish between $C$ psittaci and $C$ trachomatis, but the clinical syndromes are dissimilar enough for this to be a minor problem. Patients may show a simultaneous rise in antibody titre to a variety of organisms, which suggests that raised antibody titres to $C$ psittaci may sometimes be an anamnestic response. ${ }^{10}$ Newer methods which distinguish $C$ psittaci and $C$ trachomatis antibodies such as enzyme linked immunosorbent assay and monoclonal antibody techniques are being evaluated."

The earliest descriptions of epidemics of psittacosis in late nineteenth century Europe incriminated imported Argentinian parrots as the vectors. ${ }^{9}$ Large numbers of caged birds, domestic poultry, and wild birds are susceptible to the infection, which they may occasionally transmit to man. ${ }^{9}$ The name ornithosis is therefore sometimes used synonymously with psittacosis. Poultry workers ${ }^{12}$ and veterinarians ${ }^{13}$ may be infected, and handling feathers is a risk factor. ${ }^{13}$ Budgerigars have been responsible for about half the sporadic cases in Britain in which a vector can be identified. ${ }^{14}$

The incidence of psittacosis in Britain is increasing. Over 300 cases have been reported yearly since 1980 , and this is probably only partly owing to increased surveillance. ${ }^{2}{ }^{10}$ In one rural Cambridgeshire practice with under 5000 patients 18 symptomatic cases were recognised in 8.5 years, an annual incidence of about one in $2000 .^{10}$ In only $10-29 \%$ of cases reported in Britain and $17 \%$ of Cambridgeshire cases ${ }^{10}$ was there a history of contact with exotic, domestic, or wild birds. The lack of seasonal variation suggests that the condition is endemic. ${ }^{210}$

Is it possible, then, that psittacosis has a human reservoir? Man to man transmission, presumably by droplet spread, is considered rare but may be dramatic. In 1939 one patient infected 25 contacts, with 13 deaths, ${ }^{15}$ and recently a patient in hospital who died from psittacosis infected 11 people including a relative, medical and nursing staff, a cleaner, and a patient in the same room. ${ }^{16}$ Carriage of $C$ psittaci may continue in the sputum for as long as eight years. ${ }^{17}$

As diagnostic tests improve the epidemiology of psittacosis may become clearer; making psittacosis a notifiable disease, as suggested previously, might expedite matters. ${ }^{18}$

DAVID ISAACS

Clinical Lecturer in Paediatric Infectious Diseases,

Department of Paediatrics,

John Radcliffe Hospital,

Oxford OX3 9DU

\footnotetext{
Schachter J, Dawson CR. Human chlamydial infections. Littleton, MA: PSG Publishing Company,
1978:9-43.

Public Health Laboratory Service Communicable Disease Surveillance Centre. Trends in human ornithosis/psittacosis, 1975-80. Br Med f 1981;283:1411.
}

3 Macfarlane JT, Macrae AD. Psittacosis. Br Med Bull 1983;39:163-7.

Dymock IW, Lawson JM, Mackennan WJ, Ross CAC. Myocarditis associated with psittacosis. $B$

F Clin Pract 1971;25:240-2.
Coll R, Horner I. Cardiac involvement in psittacosis. Br Med $\mathcal{F}$ 1976;iv:35-6.

Jariwalla AG, Davies BH, White J. Infective endocarditis complicating psittacosis: response to

Levison DA, Guthrie W, Ward C, Green DM, Robertson PGC. Infective endocarditis as part of psittacosis. Lancet 1971;ii:844-7.

alton KW. The pathology of a fatal case of psittacosis showing intracytoplasmic inclusions in the meninges. Pounal of Patholog and Bact

venereum agents. In: Horsfall FL, Tamm I, eds. Viral and rickettsial infections of man. 4th ed. London: Pitman, 1965:1006-41.

11 Nagington J. Psittacosis/ornithosis in Cambridgeshire 1975-1983. F Hyg 1984;92:9-19. antibody to Chlamydia trachomatis and Chlamydia psittaci. F Lab Clin Med 1983;102:918-25. Andrews B, Major R, Palmer SR. Ornithosis in poultry workers. Lancet 1981; $;: 632-4$.

13 Palmer SR, Andrews BE, Major R. A common source outbreak of ornithosis in veterinary surgeons. Lancet 1981 ;ii:798-9.

Grist NR. Psittacosis. Br Med F 1972; 378.

Meyer KF. Ecology of psittacosis and ornithosis. Medicine 1942;21:175-206.

Broholm K, Bottiger M, Jernelius H, Johannson M, Grandien M, Solver K. Ornithosis as a nosocomial infection. Scand f Infect Dis 1977;9:263-7.

Infect Dis 1951;88:109-25.

Anonymous. Psittacosis [Editorial]. Lancet 1973; ii: 1246.

\section{Disaster at the dining table}

To die from a cardiac arrest resulting from a myocardial infarction is an unfortunate tragedy, but to die from a piece of food having "gone down the wrong way" seems a calamity of catastrophic proportion.

Not surprisingly, then, whenever I talk about cardiopulmonary resuscitation, whether the audience is medical or lay, I am invariably persuaded to spend a lot of time on the resuscitative manoeuvres described by Heimlich. ${ }^{1}$ We need to remember, however, that many cases of sudden choking occurring during meals are due to cardiac ischaemia simulating food impaction. ${ }^{2}$ The victim often clasps his neck or upper chest because of the feeling of pain, panic, and constriction in that area; onlookers may suspect food impaction because of their own experiences of mild choking on food. There are other causes of "collapse" while eating, but when choking seems to be the main presenting symptom the most useful differential diagnosis is between myocardial ischaemia and food impaction.

Food impaction is likely when the victim has been eating with dentures (which disguise the tactile perception of food quality), is edentulous and eating without dentures, is a talkative eater, a food gobbler, or an excessive drinker. True chokers do not lose consciousness for some time but are unable to speak-respiratory silence is more sinister than noisy respiration. Vigorous inspiratory attempts by the victim seem only to increase the impaction.

Typically, the victim follows one of two courses of action. Most commonly he seeks early refuge in the nearest lavatory or kitchen and leaves the dining table without a word-often remarkably unnoticed by most other diners. By this decision he either survives or dies with relative dignity, unless he is pursued into his sanctuary by a wary fellow diner. Perhaps the more extravert will choose to stay put and seek help. Some may have learnt the sign of food impaction, which is placing the skin web between the extended forefinger and thumb of the hand against the larynx. The subject's appraisal of his own catastrophe may, of course, not be accurate-but certainly the rescuer is more justified in concentrating on food impaction in the first instance.

If the presumptive diagnosis is food impaction, the rescuer must be assertive and encourage coughing or vomiting. While the victim remains conscious he should be urged to explore his throat with his own fingers while leaning forward in a sitting position with the rescuer thumping his back. Back thumping cannot be expected to disimpact food or create an expiration, but it seems to stimulate coughing and is a time honoured and expected 